\title{
Perfect Taxation with Imperfect Competition
}

by

\author{
Alan J. Auerbach \\ University of California, Berkeley and NBER
}

James R. Hines Jr.

University of Michigan and NBER

February 2001

We thank Gareth Myles, Harvey Rosen, Agnar Sandmo, and participants in the CESifo conference, Public Finances and Public Policy in the New Millennium, Munich, January 2001, for helpful comments on earlier drafts. 


\title{
Perfect Taxation with Imperfect Competition
}

\begin{abstract}
This paper analyzes features of perfect taxation - also known as optimal taxation - when one or more private markets is imperfectly competitive. Governments with perfect information and access to lump-sum taxes can provide corrective subsidies that render outcomes efficient in the presence of imperfect competition. Relaxing either of these two conditions removes the government's ability to support efficient resource allocation and changes the perfect policy response. When governments cannot use lump-sum taxes, perfect tax policies represent compromises between the benefits of subsidizing output in the imperfectly competitive sectors of the economy and the costs of imposing higher taxes elsewhere. This tradeoff is formally identical for ad valorem and specific taxes, even though ad valorem taxation is welfare superior to specific taxation in the presence of imperfect competition. When governments have uncertain knowledge of the degree of competition in product markets, perfect corrective tax policy is generally of smaller magnitude than that when the degree of competition is known with certainty.
\end{abstract}

JEL Classification: H21, D43.

\author{
Alan J. Auerbach \\ Department of Economics \\ 549 Evans Hall \\ University of California \\ Berkeley, CA 94720-3880 \\ auerbach@econ.berkeley.edu
}

James R. Hines Jr.

Office of Tax Policy Research

University of Michigan Business School

701 Tappan Street

Ann Arbor, MI 48109-1234

jrhines@umich.edu 


\section{Introduction}

Perfect taxation - or, as it is more commonly known, optimal taxation - typically entails distorting the economy in order to redistribute resources, provide public goods, or advance other government objectives. Tax policy is defined to be "perfect" if it minimizes distortions and thereby maximizes economic efficiency subject to meeting other government requirements. In the case of economies already distorted by imperfect competition in private markets, corrective taxation has the potential to enhance the efficiency of private resource allocation. In order to realize this potential, governments must be able and willing to use their available tax instruments in an informed and sensible fashion.

Richard Musgrave's $90^{\text {th }}$ birthday is an appropriate occasion to reexamine the features of perfect taxation, since much of Musgrave's work is devoted to characterizing optimal government policies. His influential classic The Theory of Public Finance (1959) categorizes these settings, providing nuggets of detailed insight while embedding its analysis in a general equilibrium consideration of the many ramifications of government policy. On the subject of imperfect competition, Musgrave (1959, pp. 149-150) describes the corrective subsidy, following it with the observation, "Since the assumption of pure competition is unrealistic, our earlier conclusions must be qualified accordingly. At the same time, allocation in the market is not altogether chaotic. Therefore, we are still well advised to prefer the general tax unless there is a clear case for correcting a specific imperfection."

The purpose of this paper is to consider in some detail the nature of perfect tax policies in imperfectly competitive markets. Section 2 uses a partial equilibrium setting to characterize tax policies that induce imperfectly competitive firms to select efficient output levels. These policies generally take the form of subsidies that encourage firms to expand output. Section 3 then 
reviews several of the general second-best welfare issues that arise whenever governments are forced to rely on distortionary tax instruments in order to raise revenue.

Section 4 analyzes the impact of distortionary taxation on the design of specific taxation in the presence of imperfect competition. The need to raise tax revenue with distortionary instruments naturally dampens the enthusiasm of the government to provide subsidies to output by firms in imperfectly competitive industries. Section 5 considers the same issues with ad valorem rather than specific taxation. While ad valorem taxes are generally welfare-superior to specific taxes in environments with imperfect competition, perfect government policy with either type of tax entails the same tradeoffs between optimal correction of market imperfection and the cost of raising revenue with distorting taxes.

Section 6 offers a numerical analysis of perfect corrective taxation (of both the specific and ad valorem variety) in a simple economy. Section 7 investigates the impact on government policy of uncertainty over the degree of market competition. The perfect response to uncertainty is generally to reduce the magnitude of the corrective tax policy, since states of the world in which little or no correction is necessary are also those in which corrective policies have the greatest market impact. Section 8 is the conclusion.

\section{Perfect commodity taxation with Cournot competition}

It is helpful to start by considering the behavior of a firm acting as a Cournot competitor in an industry with a fixed number $(n)$ of firms. ${ }^{1}$ Firms in this industry produce homogenous products. The government imposes a specific tax on output at rate $t$, so firm $i$ 's profit is given by

\footnotetext{
${ }^{1}$ The analysis in this section, and in several of the sections that follow, draws heavily on that provided in Auerbach and Hines (2001). For an early analysis of the impact of taxation in the presence of monopoly, see Cournot (1838) and Edgeworth (1925).
} 


$$
P x_{i}-t x_{i}-C\left(x_{i}\right)
$$

in which $\mathrm{P}$ is the market price of the firm's output, $x_{i}$ the quantity it produces, and $C\left(x_{i}\right)$ the cost of producing output level $x_{i}$. In this partial-equilibrium setting, it is appropriate to take $P$ to be a univariate function of industry output, denoted $X$.

The firm's first-order condition for profit maximization is

$$
P+x_{i} \frac{d P}{d X}(1+\theta)-t=C^{\prime}\left(x_{i}\right)
$$

in which 2 is firm $i$ 's conjectural variation, corresponding to $\left(\frac{d X}{d x_{i}}-1\right)$. Differing market structures correspond to differing values of 2. In a Cournot-Nash setting, in which firm $i$ believes that its quantity decisions do not affect the quantities produced by its competitors, then $2=0$. In a perfectly competitive setting, $2=-1$. Various Stackelberg possibilities correspond to values of 2 that can differ from these, and indeed, need not lie in the [-1, 0] interval.

It is useful to consider the pricing implications of (2). Differentiating both sides of (2) with respect to $t$, taking 2 to be unaffected by $t$, and limiting consideration to symmetric equilibria (so that $x_{i}=\frac{X}{n}, C\left(x_{i}\right)=C(X / n)$, and, since $\frac{d X}{d t}=\frac{d P / d t}{d P / d X}$, it follows that $\left.\frac{d x_{i}}{d t}=\frac{d P / d t}{n d P / d X}\right)$, then

$$
\frac{d P}{d t}=\left\{1+\frac{1+\theta}{n}(1+\eta)-\frac{C^{\prime \prime}(X / n)}{n d P / d X}\right\}^{-1}
$$


in which $\eta \equiv \frac{d^{2} P}{d X^{2}} \frac{X}{d P / d X}$ is the elasticity of the inverse demand function for $X$. From (3), it is clear that $\frac{d P}{d t}$ can exceed unity, a possibility that is consistent with the firm's second-order condition for profit maximization and with other conditions (discussed by Seade, 1980a, 1980b) that correspond to industry stability. The possibility that $\frac{d P}{d t}$ exceeds unity corresponds to situations in which the specific tax is overshifted. Overshifting has intrigued public finance economists at least since the time of Edgeworth.

Equations (2) and (3) identify the potential welfare impact of taxation in the presence of imperfect competition. From (2), the combination of imperfect competition $(2>-1)$ and a downward-sloping inverse demand function $\left(\frac{d P}{d X}<0\right)$ implies that firms choose output levels at which price exceeds marginal cost. Hence there is deadweight loss in the absence of taxation, and, in this simple partial equilibrium setting, tax policies that stimulate additional output reduce deadweight loss, while those that reduce output increase it. In some circumstances the imposition of a tax may reduce industry output sufficiently that after-tax profits actually rise.

Tax policy can be used to reduce or eliminate the allocative inefficiency due to imperfect competition, though other policy instruments (such as antitrust enforcement) are also typically available and may be more cost-effective at correcting the problem. ${ }^{2}$ Taking alternative remedies to be unavailable, the perfect policy, if the government has access to lump-sum

\footnotetext{
${ }^{2}$ One possibility, explored by Katz and Rosen (1985), is that tax authorities design corrective policies on the basis of imperfect understanding of the extent of competition in oligopolistic industries.
} 
taxation, is to guarantee marginal cost pricing by setting $t=\frac{X}{n} \frac{d P}{d X}(1+\theta)$. $^{3}$ Since $\frac{d P}{d X}<0$, this corrective method entails subsidizing the output of the imperfectly competitive industry.

Quite apart from what might think about the normative desirability of offering subsidies to oligopolists, ${ }^{4}$ any such corrective scheme encounters three immediate difficulties. The first is that government funds used to subsidize the output of oligopolists must be obtained with taxes that typically distort the rest of the economy. The second is that the degree of competition in an oligopoly is typically not known with certainty. And the third is that subsidies encourage industry entry, which can reduce the oligopolistic cohesion of competitors but may do so at the cost of wasted resources, since a firm's average cost typically exceeds its marginal cost in these settings. Sections 4 and 5 consider the implications of distortionary taxation for perfect corrective taxation and Section 7 introduces uncertainty. ${ }^{5}$

\section{Optimal taxation}

In order to evaluate the effect of costly tax revenue on the design of perfect corrective policies, it is necessary to impose an exogenous revenue requirement on a setting in which the government has access to distortionary tax instruments. Ramsey (1927) introduced this problem and analyzed its main features. This section first reviews the properties of the basic Ramsey result and then considers important extensions to cases in which producer prices change and in which there are consumption externalities.

\footnotetext{
${ }^{3}$ Such a corrective subsidy was proposed by Robinson (1933, pp. 163-165), who attributes it to her husband and presents it as an "ingenious but impractical scheme." For an elaboration, see Higgins (1943).

${ }^{4}$ See Musgrave (1976).

${ }^{5}$ The issue of entry is considered in Auerbach and Hines (2001).
} 


\subsection{Distortionary tax revenue}

The simplest version of the Ramsey tax problem abstracts from population heterogeneity and posits that the government must raise a fixed sum of tax revenue with proportional commodity taxes, leaving to the side how such revenue is to be spent. With a population of identical individuals, typically analyzed as a single representative individual, the goal of perfect tax design is to minimize the excess burden associated with raising the needed revenue. We typically rationalize government's inability to use lump-sum taxes by saying that such taxes are inequitable, although this may seem a bit forced in a setting with identical individuals. It may help to think of this simple problem as a necessary building block, rather than as one that adequately models a realistic situation.

The representative consumer maximizes utility, $U(\mathbf{x})$, over a vector of commodities $x_{i}(i=$ $0,1, \ldots, N)$, subject to the budget constraint $\mathbf{p} \cdot \mathbf{x} \leq y$, where $\mathbf{p}$ is the corresponding vector of consumer prices and $y$ is lump-sum income. To raise the required level of revenue, $R$, the government imposes a vector of specific taxes on the commodities, $\mathbf{t}$, driving a wedge between consumer prices and producer prices, q. It is useful to assume initially that this vector of producer prices is fixed. With given producer prices, the government in setting tax rates is effectively choosing the consumer price vector, since $\mathbf{p}=\mathbf{q}+\mathbf{t}$. Thus, the government's optimal tax problem can be modeled as

$$
\max _{p} V(\mathbf{p}, y), \text { subject to }(\mathbf{p}-\mathbf{q})^{\prime} \mathbf{x} \geq R
$$

where $V(\cdot)$ is the household's indirect utility function.

With no lump-sum income, two tax systems are equivalent if they differ by proportional taxes on all commodities. Without lump-sum income one is therefore free to normalize one of 
the taxes, say on good 0, to zero, and for convenience choose the same good as numeraire, i.e., $q_{0}$ $=p_{0}=1$. The maximization problem in (4), with the multiplier $\mu$ associated with the budget constraint, yields $N$ first-order conditions:

$$
-\lambda x_{i}+\mu\left[x_{i}+\sum_{j} t_{j} \frac{d x_{j}}{d p_{i}}\right]=0 \quad i=1, \ldots, N
$$

in which $\lambda \equiv \partial V(\mathbf{p}, y) / \partial y$ is the marginal utility of income. Making use of the Slutsky decomposition, (5) implies

$$
\sum_{j} t_{j} S_{j i}=-\frac{(\mu-\alpha)}{\mu} x_{i} \quad i=1, \ldots, N
$$

where $S_{j i}$ is the $j i^{\text {th }}$ element of the Slutsky matrix $S \equiv \frac{d \mathbf{x}^{c}}{d \mathbf{p}}$ and $\alpha=\lambda+\mu \sum_{j} t_{j} \frac{d x_{j}}{d y}$ is the "social" marginal utility of income that includes the value of the additional tax revenue raised when the household receives another unit of income. ${ }^{6}$ Before interpreting expression (6), it is useful to consider the more general case of variable producer prices.

\subsection{Changing producer prices}

Since the excess burden of a tax is a function of the extent to which the tax changes producer prices, it follows intuitively that allowing producer prices to vary alters the first-order conditions for the optimal tax schedule. Let the general production be characterized by

\footnotetext{
${ }^{6}$ Samuelson (1951) uses the symmetry of the Slutsky matrix $\left(S_{i j}=S_{j i}\right)$ to interpret (3.9) as implying that optimal taxes entail equiproportionate compensated reductions in demands for all commodities. While valid locally, this interpretation relies on constancy of the elements of the Slutsky matrix as tax rates change, a feature they do not generally exhibit.
} 


$$
f(\mathbf{z}) \leq 0
$$

where $\mathbf{z}$ is the production vector and perfect competition insures that $q_{i} / q_{j}=f_{i} / f_{j} \forall i, j$. Without loss of generality, the units of the production function can be chosen such that $q_{i}=f_{i}$. If there are constant returns to scale, then $f(\cdot)$ is homogeneous of degree zero in $\mathbf{z}$. Otherwise, there may be pure profits, $\pi=\mathbf{q}^{\prime} \mathbf{z}>0$.

With changing producer prices, it is not appropriate to specify the constraint in the optimal tax problem as a scalar value of tax revenue to be collected, so it is necessary to posit that the government absorbs a vector $\mathbf{R}$ of commodities. This implies that the consumption vector $\mathbf{x}$ satisfies $f(\mathbf{x}+\mathbf{R}) \leq 0$, thereby incorporating both revenue and production constraints. The optimal tax problem, then, is to maximize the indirect utility function $V(\mathbf{p}, \pi)$ subject to this constraint, and not that given in (4). The associated Lagrangean expression is

$$
V(\mathbf{p}, \pi)-\mu f(\mathbf{x}+\mathbf{R})
$$

and the government's problem is still that of choosing the consumer price vector $\mathbf{p}$, rather than the tax vector $\mathbf{t}$, even though the relationship between changes in the two vectors is more complicated than when producer prices are fixed. ${ }^{7}$ The resulting first-order conditions are (using the normalized form of production function) ${ }^{8}$

$$
-\lambda x_{i}+\lambda \frac{d \pi}{d p_{i}}+\mu\left[-\sum_{j} q_{j} \frac{d x_{j}}{d p_{i}}\right]=0 i=1, \ldots, N
$$

\footnotetext{
${ }^{7}$ As discussed in Auerbach (1985), $d \mathbf{p} / d \mathbf{t}=[I-H S]^{-1}$, where $H$ is the Hessian of $f(\cdot)$, so there is a one-to-one relationship between changes in $\mathbf{t}$ and changes in $\mathbf{p}$ as long as $[I-H S]$ is of full rank.
} 
Differentiating the household's budget constraint $\mathbf{p}^{\prime} \mathbf{x}=\pi$ with respect to $p_{i}$ yields

$$
x_{i}+\sum_{j} p_{j} \frac{d x_{j}}{d p_{i}}-\frac{d \pi}{d p_{i}}=0 i=1, \ldots, N
$$

and adding the left side of this equation to the expression inside the brackets in (9) yields

$$
-\lambda x_{i}+\lambda \frac{d \pi}{d p_{i}}+\mu\left[x_{i}+\sum_{j} t_{j} \frac{d x_{j}}{d p_{i}}-\frac{d \pi}{d p_{i}}\right]=0 \quad i=1, \ldots, N
$$

Since producer prices, and hence profits, change with $\mathbf{p}$, the derivative $d x_{j} / d p_{i}$ in (11) includes the indirect effect of $p_{i}$ on profits through changes in production:

$$
\frac{d x_{j}}{d p_{i}}=\frac{\partial x_{j}}{\partial p_{i}}+\frac{d x_{j}}{d y} \cdot \frac{d \pi}{d p_{i}}
$$

Using this and the above definition of the marginal social utility of income, $\alpha,(11)$ can be rewritten as

$$
-\lambda x_{i}+\mu\left[x_{i}+\sum_{j} t_{j} \frac{\partial x_{j}}{\partial p_{i}}-\left(\frac{\mu-\alpha}{\mu}\right) \frac{d \pi}{d p_{i}}\right]=0 \quad i=1, \ldots, N
$$

or, using the Slutsky decomposition, as

$$
-\sum_{j} t_{j} S_{j i}=\frac{(\mu-\alpha)}{\mu}\left(x_{i}-\frac{d \pi}{d p_{i}}\right) \quad i=1, \ldots, N
$$

\footnotetext{
${ }^{8}$ Note that we still assume a zero tax rate on the numeraire commodity, good 0 . In the presence of pure profits, the ability to impose a tax on this good would facilitate a revenue-raising nondistortionary uniform tax on all commodities, equivalent to a lump-sum profits tax.
} 
which differs from expression (6), the first-order condition in the case of fixed producer prices, by the term $d \pi / d p_{i}$ on the right side. Thus, if there are constant returns to scale $(\pi \equiv 0)$, the firstorder conditions are identical (Diamond and Mirrlees 1971). The same is true if the government imposes a pure profits tax, so that the after-tax value of $y$ accruing to households is uniformly zero (Stiglitz and Dasgupta 1971).

The left side of (14) equals the marginal excess burden associated with an increase in $p_{i}$. The second term on the right side of (14) is the net compensation required to maintain the individual's utility as $p_{i}$ rises ${ }^{9}$ which, by definition, exceeds the marginal revenue raised by the marginal excess burden induced by the price change. Thus, (14) says that the excess burden of a marginal increase in any tax must be proportional to the sum of marginal revenue plus marginal excess burden, or:

$$
\frac{d E B}{d p_{i}}=\frac{(\mu-\alpha)}{\mu}\left(\frac{d R}{d p_{i}}+\frac{d E B}{d p_{i}}\right) \quad i=1, \ldots, N
$$

It follows that the marginal excess burden per dollar of revenue raised, $(\mu-\alpha) / \alpha$, is also constant, which is an intuitive condition for minimizing the total excess burden induced by raising a given amount of revenue from alternative sources.

\subsection{Externalities}

A similarly intuitive set of results appears when the simple Ramsey problem is extended to incorporate externalities, as in Sandmo (1975). Suppose that an externality, E, enters into

${ }^{9}$ This term equals $-\frac{d V(\mathbf{p}, y) / d p_{i}}{d V(\mathbf{p}, y) / d y} ;$ according to Roy's identity, this equals the net increase in income required to maintain the household's utility level as $p_{i}$ increases. 
each person's utility function and cannot be avoided, so that the representative individual's indirect utility function may be written $V(\mathbf{p} ; E)$. Suppose also, for simplicity, that the externality is the product of aggregate consumption of a single good, say the good with the highest index, $N$. Then, the Lagrangean,

$$
H V\left(\mathbf{p} ; X_{N}\right)-\mu f(\mathbf{X})
$$

implies the following $N$ first-order conditions with respect to the prices of goods $1, \ldots, N$ (compare to 6):

$$
-\lambda x_{i}+\mu\left[x_{i}+\sum_{j} t_{j}^{*} \frac{d x_{j}}{d p_{i}}\right]=0 i=1, \ldots, N
$$

where

$$
\begin{array}{ll}
t_{j}^{*}=t_{j} & j \neq N \\
t_{N}^{*}=t_{N}+\frac{H V_{E}}{\mu}=t_{N}+\frac{H V_{E} / \lambda}{\mu / \lambda}
\end{array}
$$

Expression (17) is the standard perfect tax solution, except that it calls for the tax on the externality-producing good, $t_{N}$, to equal the sum of the "perfect" tax that ignores the externality, $t_{N}^{*}$, plus a term that reflects the cost of the externality. This second term equals the corrective Pigouvian tax - the social cost per unit of consumption of the good, measured in terms of the numeraire commodity - divided by the marginal cost of public funds, $\mu \lambda$. 


\section{Perfect specific taxation with distortionary tax instuments}

In order to explore the impact of distortionary taxation on perfect corrective taxation, consider the setup of section 3.1, in which all commodities are produced at constant cost. There are $N+1$ commodities, of which the first $N$, indexed $0, \ldots, N-1$, are produced by competitive firms, and commodity $N$ is produced in an imperfectly competitive market whose pricing satisfies (2). ${ }^{10}$ Denoting the (constant) per-unit production cost of commodity $i$ by $q_{i}$, it follows that $p_{i}=q_{i}+t_{i}, \forall i=0, \ldots, N-1$. As in section 3.1, we assume that the tax on the numeraire commodity, good 0 , equals 0 . Firms in the imperfectly competitive industry generate profits, and someone in the economy receives these profits as income. ${ }^{11}$ Taking consumers in the economy to be identical, it follows that the utility of the representative consumer can be represented by

$$
V(\mathbf{p}, \mathrm{B})
$$

in which $\mathbf{p}$ is the vector of $N+1$ commodity prices, and $\mathrm{B}$ represents profits earned by the imperfectly competitive firms. Commodity demands are then functions of ( $\mathbf{p}, \mathbf{B})$, but to simplify the calculations that follow, we consider the case in which firms ignore the indirect impact of their pricing decisions on demand through induced changes in profits. The representative firm's

\footnotetext{
${ }^{10} \mathrm{We}$ follow much of the literature in assuming that preferences and technology support a unique stable market equilibrium, which, as Roberts and Sonnenschein (1977) note, need not exist in the presence of imperfect competition. Guesnerie and Laffont (1978) analyze cases in which preferences and production technologies make it impossible for any tax policies to support first best outcomes. They note that, in other cases, corrective government policies produce outcomes that are highly unstable.

${ }^{11}$ In the competitive context, assuming a zero tax rate on one commodity restricts the government effectively from imposing a tax on pure profits through a uniform tax on all commodities. Here, though, before-tax profits would respond to such uniform taxation, leaving the government's problem unchanged. See Auerbach and Hines (2001) for a more formal demonstration of this point.
} 
first-order condition for profit maximization becomes $p_{N}+\frac{X_{N}(1+\theta)}{n\left(\partial X_{N} / \partial p_{N}\right)}-t_{N}=q_{N}$. Thus, the price-cost margin imposed by imperfect competition is $m=-\frac{X_{N}(1+\theta)}{n\left(\partial X_{N} / \partial p_{N}\right)}$.

The optimal taxation problem can be conveniently analyzed by maximizing (18) over the choice of $\mathbf{p}, t_{N}$, and $\mathrm{B}$, subject to the constraints that

$$
\begin{aligned}
& \sum_{j=1}^{N} t_{j} X_{j}=R \\
& \left(p_{N}-t_{N}-q_{N}\right) X_{N}=\pi \\
& -\frac{X_{N}}{n} \frac{(1+\theta)}{\partial X_{N} / \partial p_{N}}=p_{N}-t_{N}-q_{N} .
\end{aligned}
$$

This approach to the optimal tax problem defines tax rates on the first $N-1$ commodities implicitly by the relationship $t_{i}=p_{i}-q_{i}$. Equation (19) corresponds to the government's budget constraint, (20) to the definition of profits, and (21) to the first-order condition for profit maximization in the imperfectly competitive industry. ${ }^{12}$

The first order condition corresponding to maximizing (18) over the choice of $p_{i}(i<N)$, subject to (19), (20), and (21), may be written ${ }^{13}$ :

$$
\begin{aligned}
& -\lambda X_{i}+\mu\left[X_{i}+\sum_{j=1}^{N} t_{j} \frac{\partial X_{j}}{\partial p_{i}}\right]+\varphi_{1}\left[\left(p_{N}-t_{N}-q_{N}\right) \frac{\partial X_{N}}{\partial p_{i}}\right] \\
& +\varphi_{2}\left[\frac{\left(p_{N}-t_{N}-q_{N}\right)}{X_{N}} \frac{\partial X_{N}}{\partial p_{i}}-\frac{\left(p_{N}-t_{N}-q_{N}\right)}{\partial X_{N} / \partial p_{N}} \frac{\partial^{2} X_{N}}{\partial p_{N} \partial p_{i}}\right]=0
\end{aligned}
$$

\footnotetext{
${ }^{12}$ See Myles (1987, 1989, and 1995, pp. 363-369) for an alternative approach to characterizing the solution to the optimal tax problem in the presence of imperfect competition.
} 
in which, as before, the Lagrange multiplier : is associated with the revenue constraint, while the new Lagrange multipliers $\varphi_{1}$ and $\varphi_{2}$ correspond to the additional constraints (20) and (21). The first-order condition corresponding to the choice of $p_{N}$ is

$$
\begin{aligned}
& -\lambda X_{N}+\mu \sum_{j=1}^{N} t_{j} \frac{\partial X_{j}}{\partial p_{N}}+\varphi_{1}\left[\left(p_{N}-t_{N}-q_{N}\right) \frac{\partial X_{N}}{\partial p_{N}}+X_{N}\right] \\
& +\varphi_{2}\left[-X_{N}+\frac{\left(p_{N}-t_{N}-q_{N}\right)}{X_{N}} \frac{\partial X_{N}}{\partial p_{N}}-\frac{\left(p_{N}-t_{N}-q_{N}\right)}{\partial X_{N} / \partial p_{N}} \frac{\partial^{2} X_{N}}{\partial p_{N}^{2}}\right]=0
\end{aligned}
$$

The first-order conditions corresponding to choices of $t_{N}$ and $\mathrm{B}$ are given by

$$
\begin{aligned}
& \mu X_{N}-\varphi_{1} X_{N}+\varphi_{2}=0 \\
& \lambda+\mu \sum_{j=1}^{N} t_{j} \frac{\partial X_{j}}{\partial \pi}-\varphi_{1}=0 .
\end{aligned}
$$

To simplify and interpret these first-order conditions, we note first that by substituting (23) into (22b), we obtain (22a), for $i=N$. Thus, this expression holds for $i=1, \ldots, N$. Next, it is possible to combine (23) and (24) to solve for the multipliers $\varphi_{1}$ and $\varphi_{2}$ in terms of other parameters. Doing so, we find that $\varphi_{1}=\lambda+\mu \sum_{j=1}^{N} t_{j} \frac{\partial X_{j}}{\partial \pi}$, which was defined in section 3.1 as the "social" marginal utility of income, $\alpha$, and that $\varphi_{2}=-\left(\mu-\varphi_{1}\right) X_{N}=-(\mu-\alpha) X_{N}$, which expresses the deadweight loss associated with the restriction of good- $N$ consumption. Substituting these expressions into (22a), we obtain the following expression for $i=1, \ldots, N$ :

\footnotetext{
${ }^{13}$ The last term in brackets in (22a) results from substituting (21) into the actual first-order condition.
} 


$$
\begin{aligned}
& -\lambda X_{i}+\mu\left[X_{i}+\sum_{j=1}^{N} t_{j} \frac{\partial X_{j}}{\partial p_{i}}\right]+\alpha\left[\left(p_{N}-t_{N}-q_{N}\right) \frac{\partial X_{N}}{\partial p_{i}}\right] \\
& +(\mu-\alpha) X_{N}\left[-\frac{\left(p_{N}-t_{N}-q_{N}\right)}{X_{N}} \frac{\partial X_{N}}{\partial p_{i}}+\frac{\left(p_{N}-t_{N}-q_{N}\right)}{\partial X_{N} / \partial p_{N}} \frac{\partial^{2} X_{N}}{\partial p_{N} \partial p_{i}}\right]=0
\end{aligned}
$$

The second term in brackets in (25) equals $m\left(\partial X_{N} / \partial p_{i}\right)$. The third term in brackets in (25) equals the change in the price-cost margin in industry $N$ with respect to $p_{i}, \partial m / \partial p_{i}$. Since (20) and (21) together imply that $\frac{d \pi}{d p_{i}}=m \frac{\partial X_{N}}{\partial p_{i}}+X_{N} \frac{\partial m}{\partial p_{i}}$, it is possible to rewrite (25) as

$$
-\lambda X_{i}-\mu\left[X_{i}+\sum_{j=1}^{N} t_{j}^{*} \frac{\partial X_{j}}{\partial p_{i}}-\left(\frac{\mu-\alpha}{\mu}\right) \frac{d \pi}{d p_{i}}\right]=0
$$

in which

$$
\begin{array}{lll}
t_{j}^{*} & =t_{j} & j \neq N \\
t_{N}^{*} & =p_{N}-q_{N}
\end{array}
$$

is the total wedge in market $j$, equal to $t_{N}+m$ in industry $N$.

Equation (26) is analogous to (17), and carries precisely the interpretation offered by Sandmo for the perfect tax conditions in the presence of externalities. Intuitively, the "externality" in the case of imperfect competition is the outcome of the oligopolistic output selection, resulting in the extra mark-up $m$. The definition of $t_{N}^{*}$ takes into account the need to correct this pre-existing distortion. Were this the only term on the right side of (26), then it would be optimal fully to correct for the extra distortion in industry $N$ and then impose the standard perfect taxes. Presumably, the net result in industry $N$ would be an incomplete offset of the oligopolistic mark-up, the optimal tax component normally being positive. The second term 
in brackets in (26) accounts for the existence of profits, taking the form laid out in expression (13) above and explained in that context. In this instance, tax-induced price changes affect the profitability of the imperfectly competitive industry, the difference (: -") capturing the welfare effect of increasing industry profits by one unit. To the extent that a higher price of a commodity directly or indirectly augments oligopoly profits, this must be included in computing the price change's overall welfare effect. Doing so has the effect of making the price increase less attractive as a policy tool.

Although the preceding derivation of expression (26) elucidates the role played by taxes in influencing the noncompetitive industry's mark-up, one may arrive at the same result more directly by incorporating the constraints of the problem in a different manner. Doing so also facilitates an extension to the case in which more than one industry is noncompetitive. Assume that the revenue constraint still obeys (19), but that profits are now:

$$
\sum_{j=M+1}^{N}\left(p_{j}-t_{j}-q_{j}\right) X_{j}=\pi
$$

where the characterization of producer behavior in noncompetitive industries $j>M$ is

$$
p_{j}-t_{j}-q_{j}=-\frac{X_{j}}{n_{j}} \frac{\left(1+\theta_{j}\right)}{\partial X_{j} / \partial p_{j}},
$$

where $n_{j}$ and $\theta_{j}$ are defined for industry $j$ in the usual way. Combining (20') with the revenue constraint, (19), we may recast the problem as one of maximizing (18) with respect to p, subject to the constraint, 


$$
\sum_{j=1}^{N}\left(p_{j}-q_{j}\right) X_{j} \geq R+\pi
$$

where profits are given by

$$
\pi=-\sum_{j=M+1}^{N} \frac{X_{j}}{n_{j}} \frac{\left(1+\theta_{j}\right)}{\partial X_{j} / \partial p_{j}} X_{j}
$$

With $\mu$ defined as the multiplier of the constraint given in (27), the first-order conditions for this problem are:

$$
-\lambda X_{i}+\lambda \frac{d \pi}{d p_{i}}+\mu\left[x_{i}+\sum_{j}\left(p_{j}-q_{j}\right) \frac{\partial X_{j}}{\partial p_{i}}+\sum_{j}\left(p_{j}-q_{j}\right) \frac{\partial X_{j}}{\partial y} \frac{d \pi}{d p_{i}}-1\right]=0 \quad i=1, \ldots, N
$$

where, as before, $\lambda$ is the marginal utility of income and $\alpha$ is the "social" marginal utility of income. This may be rewritten to produce expression (26) above, with $t_{j}^{*}, j>M$, equal to the total wedge in industry $j$.

The preceding discussion presumes that the government is unable to use a complete set of tax instruments, being restricted instead to linear taxes on output. If the government has access to a tax on pure profits, then it can improve efficiency by using it. A 100 percent pure profit tax would effectively remove the $\frac{d \pi}{d p_{i}}$ term from equation (26), thereby modifying the perfect output tax configuration to consist of Ramsey-like revenue raising taxes plus a corrective subsidy to output in the imperfectly competitive industry. The use of pure profit taxes together with other tax instruments relies, however, on the ability of the government to identify pure profits with 
precision in all situations. Consequently, in the analysis that follows the government is assumed not to have the option of imposing pure profit taxes.

\section{Specific and ad valorem taxation}

In competitive markets the distinction between specific and ad valorem taxation arises only from minor tax enforcement considerations. In imperfectly competitive markets these two tax instruments are no longer equivalent, since the imposition of an ad valorem tax makes the tax rate per unit of sales a function of a good's price, which is partly under the control of individual firms. As a result, ad valorem and specific taxes that raise equal tax revenue will typically differ in their implications for economic efficiency, ad valorem taxation being associated with much less deadweight loss. ${ }^{14}$ Intuitively, ad valorem taxation removes a fraction (equal to the ad valorem tax rate) of a firm's incentive to restrict its output level in order to raise prices.

\subsection{Welfare effects}

Now, the government is assumed to have access both to an ad valorem tax and to a specific tax. In this setting the firm's profits equal

$$
(1-\tau) P x_{i}-t x_{i}-C\left(x_{i}\right)
$$

in which $\mathrm{J}$ is the ad valorem tax rate. Assuming the $n$-firm outcome to be symmetric, the firstorder condition for profit maximization becomes

$$
(1-\tau)\left[P+\frac{X}{n} \frac{d P}{d X}(1+\theta)\right]-t=C^{\prime}\left(\frac{X}{n}\right),
$$


and its pricing implications are

$$
\begin{gathered}
\frac{d P}{d t}=\left\{(1-\tau)\left[1+\frac{1+\theta}{n}(1+\eta)\right]-\frac{C^{\prime \prime}(x / n)}{n d P / d X}\right\}^{-1} \\
\frac{d P}{d \tau}=\left[P+\frac{X}{n} \frac{d P}{d X}(1+\theta)\right] \frac{d P}{d t} .
\end{gathered}
$$

Since a unit change in $\mathrm{J}$ raises more tax revenue than does a unit change in $t$, it is unsurprising that $\frac{d P}{d \tau}>\frac{d P}{d t}$. Much more revealing is the effect of these tax instruments normalized by dollar of marginal tax revenue. Since total tax revenue is given by $\operatorname{Rev}=\tau P X+t X$, it follows that

$$
\begin{aligned}
& \frac{d \operatorname{Rev}}{d t}=X\left(1+\tau \frac{d P}{d \tau}\right)+(t+\tau P) \frac{\partial X}{\partial P} \frac{d P}{d t} \\
& \frac{d \operatorname{Rev}}{d \tau}=P X\left(1+\frac{\tau}{P} \frac{d P}{d \tau}\right)+(t+\tau P) \frac{\partial X}{\partial P} \frac{d P}{d \tau} .
\end{aligned}
$$

In this simple partial equilibrium model, the change in deadweight loss associated with one of these tax changes is equal to the product of the induced change in $X$ and the difference between marginal cost and price. Consequently,

$$
\frac{d(D W L) / d t}{d(D W L) / d \tau}=\frac{-(\partial X / \partial P)}{-(\partial X / \partial P)} \frac{(d P / d t)}{(d P / d \tau)} \frac{\left(P-C^{\prime}\left(\frac{X}{n}\right)\right)}{\left(P-C^{\prime}\left(\frac{X}{n}\right)\right)}=\frac{d P / d t}{d P / d \tau}
$$

\footnotetext{
${ }^{14}$ Suits and Musgrave (1953) provide a classic analysis of this comparison; their treatment is greatly expanded and elaborated by Deliapalla and Keen (1992).
} 
which, together with (34a) and (34b), implies that

$$
\frac{\left[\frac{d(D W L) / d t}{d(D W L) / d \tau}\right]}{\left[\frac{d \operatorname{Rev} / d t}{d \operatorname{Re} v / d \tau}\right]}=\frac{X\left(\frac{P}{d P / d \tau}+\tau\right)+(t+\tau P) \frac{\partial X}{\partial P}}{X\left(\frac{1}{d P / d t}+\tau\right)+(t+\tau P) \frac{\partial X}{\partial P}} .
$$

From (33), $\frac{d P}{d \tau}<P \frac{d P}{d t}$, so if tax revenue is an increasing function of tax rates, then the right side of (35) is greater than unity. Hence revenue-equal substitution of ad valorem for specific taxation reduces deadweight loss at any $(t, \mathrm{~J})$ combination. ${ }^{15}$ Of course, such substitution works at the expense of firm profitability, and would, if used excessively, drive profits negative and supply presumably to zero. But assuming the firm profitability constraint not to bind, the optimal tax configuration entails ad valorem rather than specific taxation.

\subsection{Optimal taxation with distortionary ad valorem tax instruments}

The preceding comparison of ad valorem and specific taxation compares their effectiveness per dollar of foregone revenue, but does not address the question of the optimal rate of ad valorem taxation when the government is unable or unwilling to provide specific subsidies. While this problem is typically thought (e.g., Myles, 1989) to entail a very different solution than that for specific taxation, properly framed it becomes clear that the solution has the same character regardless of the type of available tax instrument.

Following the analysis of specific taxes, we seek to maximize the indirect utility function in (18) subject to the revenue constraint,

\footnotetext{
${ }^{15}$ Consequently, if the government is able to impose negative specific taxes (specific subsidies), then it can completely eliminate the distortion due to imperfect competition through a judicious combination of ad valorem tax
} 


$$
\sum_{j=1}^{N} \tau_{j} p_{j} X_{j} \geq R
$$

the definition of profits,

$$
\left(p_{N}\left(1-\tau_{N}\right)-q_{N}\right) X_{N}=\pi,
$$

and the characterization of producer behavior:

$$
\begin{aligned}
& p_{j}\left(1-\tau_{i}\right)-q_{j}=\quad 0 \quad j=1, \ldots, M \\
& -\left(1-\tau_{j}\right) \frac{X_{j}}{n_{j}} \frac{\left(1+\theta_{j}\right)}{\partial X_{j} / \partial p_{j}} \quad j=M+1, \ldots, N
\end{aligned}
$$

As before, we express this as a problem of choosing the consumer prices, $\mathbf{p}$, by using (38) to eliminate $\mathbf{t}$ from the problem and using (37) to substitute for the explicit expression for the markup, $m$. The result is that we may rewrite the problem as one of maximizing (18) with respect to p, subject to the constraint,

$$
\sum_{j=1}^{N}\left(p_{j}-q_{j}\right) X_{j} \geq R+\pi,
$$

where profits are given by

$$
\pi=\sum_{j=M+1}^{N}\left[\frac{q_{j}}{p_{j}-\phi_{j}}\right] \phi_{j} X_{j}, \quad \text { where } \phi_{j}=-\frac{X_{j}}{n_{j}} \frac{\left(1+\theta_{j}\right)}{\partial X_{j} / \partial p_{j}}
$$


Note that expression (40) differs from (28) by the term multiplying $\phi_{j} X_{j}$ on the right-hand side of (40), which equals $\left(1-\tau_{j}\right)$. Otherwise, the problem is identical to that for specific taxes, and the first-order conditions given in (26) still hold, for $\tau_{i}$ inserted in place of $t_{i} / p_{i}$. The resulting equilibrium will generally be different, of course, because profits, and hence the terms $d \pi / d p_{i}$, will be different.

\section{An example}

In order to illustrate the tradeoffs implicit in corrective tax policies with imperfect competition, it is useful to consider a concrete example. Suppose that the economy consists of identical consumers with utility functions over two goods, 1 and 2, and leisure of the form,

$$
U\left(x_{1}, x_{2}, l\right)=\left(x_{1}-a\right)^{\beta_{1}} x_{2}^{\beta_{2}} l^{\beta_{3}}
$$

where the exponents $\beta_{i}$ sum to 1 . This is the Stone-Geary or displaced Cobb-Douglas specification, where the quantity $a$ of good 1 may be interpreted as a basic need. If $a>(<) 0$, then good 1 is a relative necessity (luxury).

We assume that the labor market and the market for good 1 are competitive, but that the market for good 2 is noncompetitive in the manner discussed above. The market demands for goods 1 and 2 are:

$$
X_{1}=a+\beta_{1} \frac{y-p_{1} a}{p_{1}} ; \quad X_{2}=\beta_{2} \frac{y-p_{1} a}{p_{2}}
$$

where $y$ is the household's full income, equal to its labor endowment plus profits.

From expression (26), we obtain the following expressions for perfect taxes on goods 1 and 2, assuming that labor is untaxed: 


$$
-\lambda X_{i}+\mu\left[X_{i}+t_{1} \frac{\partial X_{1}}{\partial p_{i}}+t_{2}^{*} \frac{\partial X_{2}}{\partial p_{i}}\right]-(\mu-\alpha) \frac{d \pi}{d p_{i}}=0 \quad i=1,2
$$

which, rewritten using the demand expressions in (42), are

$$
\begin{aligned}
& (\mu-\lambda) X_{1}-\mu\left[\left(\frac{t_{1}}{p_{1}}\right) \frac{\beta_{1} y}{p_{1}}+\left(\frac{t_{2}^{*}}{p_{2}}\right) \beta_{2} a\right]-(\mu-\alpha) \frac{d \pi}{d p_{1}}=0 \\
& (\mu-\lambda) X_{2}-\mu\left[\left(\frac{t_{2}^{*}}{p_{2}}\right) X_{2}\right]-(\mu-\alpha) \frac{d \pi}{d p_{2}}=0 .
\end{aligned}
$$

The implications of these conditions depend on the manner in which taxes are imposed.

For specific taxes, because the elasticity of demand for good 2 is unity, the mark-up in industry 2 is, from equation (21):

$$
p_{2}-t_{2}-q_{2}=p_{2} \frac{(1+\theta)}{n} \text {. }
$$

Thus, profits are $\pi=p_{2} \frac{(1+\theta)}{n} X_{2}$ which, using (42), equals $\beta_{2}\left(y-p_{1} a\right) \frac{(1+\theta)}{n}$. Because the household's full income, $y$, equals its labor endowment, say $L$, plus $\pi$, one may express profits in terms of underlying parameters as:

$$
\pi=\gamma \frac{L-p_{1} a}{1-v}, \quad \text { where } v=\beta_{2} \frac{(1+\theta)}{n}
$$

Using this expression, it is possible to rewrite the first-order conditions in (44) as 


$$
\begin{aligned}
& (\mu-\lambda) X_{1}-\mu\left[\left(\frac{t_{1}}{p_{1}}\right) \frac{\beta_{1} y}{p_{1}}+\left(\frac{t_{2}^{*}}{p_{2}}\right) \beta_{2} a\right]-(\mu-\alpha)\left[-a\left(\frac{v}{1-v}\right)\right]=0 \\
& (\mu-\lambda) X_{2}-\mu\left[\left(\frac{t_{2}^{*}}{p_{2}}\right) X_{2}\right]=0 .
\end{aligned}
$$

In (47a), the impact on profits of an increase in the price of the competitive good depends on the sign of $a$. (The corresponding term in (47b) is zero, in this case.) If $a$ is positive (negative), this impact on profits is negative (positive), which will contribute, ceteris paribus, to a higher (lower) tax on that good. As will be seen shortly, this effect works in the same direction as the tax differential prevailing in the absence of imperfect competition. Rearranging expression (47b) in terms of the proportional wedge, $t_{2}^{*} / p_{2}$, and substituting this expression into (47a), we obtain the following expressions:

$$
\begin{aligned}
& \frac{t_{1}}{p_{1}}=\left(\frac{\mu-\lambda}{\mu}\right)\left(1+\frac{P_{1} \beta_{3} a}{\beta_{1} y}\right)+\frac{P_{1} a}{\beta_{1} y}\left(\frac{\mu-\alpha}{\mu}\right)\left(\frac{v}{1-v}\right) \\
& \frac{t_{2}^{*}}{p_{2}}=\left(\frac{\mu-\lambda}{\mu}\right)
\end{aligned}
$$

These expressions are informative about the ways in which different parameters affect the relative tax rates on goods 1 and 2. Consider first what happens in the absence of imperfect competition $(n=\infty$ or $\theta=1)$. In this case, taxes on the two goods will be equal only if $\beta_{3}=0$ (in which case labor is supplied inelastically and a uniform tax on the two goods is nondistortionary) or $a=0$ (in which case neither good is a relative necessity). Introducing imperfect competition works to enlarge the differential wedge between the two industries, based on the full wedge in 
industry $2, t_{2}^{*}$. However, there are limits to the conclusions one can draw based on these expressions, because they are not complete solutions for the tax rates, but depend on multipliers that are themselves endogenous. Also, the conditions for the ad valorem tax case, using the mark-up condition based on (38) instead of (45), yields somewhat messier conditions than (48a) and (48b). Thus, for further insight, we turn to numerical simulations.

Table 1 presents simulations for this Stone-Geary case, for a range of values of the basic need, $a$, and the mark-up term, $(1+\theta) / n$. In all simulations, the intensity parameters $\beta_{i}$ each equal $1 / 3$, the value of the labor endowment and all producer prices equal 1 , and required revenue equals 0.1. For ease of comparison, the taxes presented are in specific units, rather than as a fraction of the price, even in the case of ad valorem taxation.

There are a number of interesting results one can observe from inspection of the table. First, for all variations in the preference parameter $a$, the total wedge on the taxed good increases with the degree of noncompetitiveness, as tax reductions occur but do not completely offset the extra wedge induced by increases in $(1+\theta) / n$. For all values of $a$, the tax on the competitive good rises with the mark-up in industry 2 , as needed to reduce the tax rate on the noncompetitive good. Following the intuition provided based on expressions (48a) and (48b), the wedge under specific taxation between $t_{2}^{*}$ and $t_{1}$ grows with $(1+\theta) / n$, becoming more negative when $a>0$, more positive when $a<0$, and remaining constant when $a=0$.

When $(1+\theta) / n>0$, the tax on good 2 is generally higher in the case of ad valorem taxation, because the ad valorem tax acts to moderate noncompetitive behavior. Because of this moderation, the total wedge facing purchases of good 2 is sometimes lower under ad valorem taxation, despite the higher tax. The one exception to the rule of higher taxation of good 2 under ad valorem taxation is in the last row of the table. Here, the tax on good 2 is initially low, even 
without noncompetitive behavior, because good 1 is a relative necessity $(a>0)$. As $(1+\theta) / n$ rises, this contributes to a further lowering of $t_{2}$, to the point that it becomes negative when $(1+\theta) / n=.2-$ corresponding to a five-firm industry under Cournot conjectures. However, once the tax rate on good 2 is negative, applying it as an ad valorem tax exacerbates noncompetitive behavior. This can be seen by the fact that the mark-up (the difference between $t_{2}$ and $t_{2}^{*}$ ) is higher for the ad valorem tax case in this row, in contrast to the rest of the table.

\section{Uncertainty}

One of the difficulties facing tax authorities attempting to implement perfect corrective policies is that the extent of imperfect competition in an industry is generally not known with certainty. This section explores the impact of uncertainty on the design of corrective policy. We consider the case in which the extent of competition, as captured by 2 , is unknown. As in section 4 above, the government has access to specific tax instruments with which to tax industries producing output at constant costs. As a result, the government directly controls the prices of commodities other than that produced by imperfectly competitive firms. We also assume here, to keep the analysis tractable, that the government has no revenue needs and has access to lump-sum taxation.

Taking the measure of welfare to be expected utility, the government maxmizes

$$
E\left[V\left(\mathbf{p}_{0}, p_{N}, \mathrm{~B}-T\right)\right]
$$

in which $\mathbf{p}_{0}$ is the vector of $N$ commodity prices for goods produced by firms in competitive industries, $p_{N}$ is the price of the output sold in the imperfectly competitive industry, B represents 
profits earned by the imperfectly competitive firms, and $T$ equals lump-sum taxes. $E[A$ is the expectations operator.

The government selects a vector of commodity taxes $\mathbf{t}$ and lump-sum taxes $T$ to maximize (49) subject to:

$$
\begin{aligned}
& \sum_{j=1}^{N} t_{j} X_{j}+T=0 \\
& \left(p_{N}-t_{N}-q_{N}\right) X_{N}=\pi \\
& -\frac{X_{N}}{n} \frac{(1+\theta)}{\partial X_{N} / \partial p_{N}}=p_{N}-t_{N}-q_{N} .
\end{aligned}
$$

Denoting the imperfectly competitive markup $\left(p_{N}-t_{N}-q_{N}\right)$ by $m$, it follows that the government maximand can be written as:

$$
E\left[V\left(p_{0},\left\{q_{N}+t_{N}+m(t, \theta)\right\},\left\{X_{N}(t, \theta) m(t, \theta)+\sum_{j=1}^{N} t_{j} X_{j}(t, \theta)\right\}\right)\right],
$$

in which use is made of reduced-form functions to denote the dependency of $m$ and $X_{j}$ on prices and income that in turn are functions of $\mathbf{t}$ and $\mathbf{2}$. The first-order conditions corresponding to the maximum of (53) over the choice of the elements of the vector $\mathbf{t}$ are:

$$
E\left[\lambda(t, \theta)\left\{m(t, \theta) \frac{\partial X_{N}(t, \theta)}{\partial t_{i}}+\sum_{j=1}^{N} t_{j} \frac{\partial X_{j}(t, \theta)}{\partial t_{i}}\right\}\right]=0, \forall i
$$


In the absence of uncertainty over the value of 2 , it is clear that (54) is satisfied by a tax vector in which $t_{j}=0 \forall j<N$ and $t_{N}=-m$, as analyzed earlier. Equation (54) illustrates the channels through which uncertainty over the extent of competition influences the optimal tax rule. One such channel concerns risk aversion as reflected by the $\lambda(t, \theta)$ function. The marginal utility of income, 8 , is generally a decreasing function of 2 , since a greater degree of monopoly leads to higher prices (recall that nominal income is fixed) and therefore lower utility associated with marginal nominal income. The extent to which 2 affects 8 is, however, attenuated by the reduced utility due to monopoly, and the associated higher marginal utility of income.

It is useful to put risk considerations aside, in order to focus on issues that are specific to the imperfectly competitive setting of the problem. To do so we take 8 in (54) to be unaffected by 2 , and consider the simplifying case in which $t_{j}=0 \forall j<N$. Then (54) implies:

$$
E\left[\left(m(t, \theta)+t_{N}\right) \frac{\partial X_{N}(t, \theta)}{\partial t_{N}}\right]=0 .
$$

Denoting the expectation of $m, E[m(t, \theta)]$, by $\bar{m}(t)$, equation (55) indicates that the dependency of $\frac{\partial X_{N}}{\partial t_{N}}$ on 2 implies that the perfect corrective tax is not simply $t_{N}=-\bar{m}(t)$. If we express this partial derivative as:

$$
\frac{\partial X_{N}(t, \theta)}{\partial t_{N}}=\frac{\partial X_{N}(t, \theta)}{\partial p_{N}} \frac{\partial p_{N}(t, \theta)}{\partial t_{N}}
$$

then the first order condition (55) becomes: 


$$
E\left[\frac{\partial X_{N}(t, \theta)}{\partial p_{N}}\left(m(t, \theta)+t_{N}\right) \frac{\partial p_{N}(t, \theta)}{\partial t_{N}}\right]=0 .
$$

This condition is satisfied when

$$
\left(\bar{m}(t)+t_{N}\right) E\left[\frac{\partial X_{N}(t, \theta)}{\partial p_{N}} \frac{\partial p_{N}(t, \theta)}{\partial t_{N}}\right]+\operatorname{Cov}\left\{m(t, \theta), \frac{\partial X_{N}(t, \theta)}{\partial p_{N}} \frac{\partial p_{N}(t, \theta)}{\partial t_{N}}\right\}=0,
$$

so that the optimal tax rule is:

$$
t_{N}=-\bar{m}(t)\left[1+\frac{\operatorname{Cov}\left\{m(t, \theta), \frac{\partial X_{N}(t, \theta)}{\partial p_{N}} \frac{\partial p_{N}(t, \theta)}{\partial t_{N}}\right\}}{\bar{m}(t) E\left[\frac{\partial X_{N}(t, \theta)}{\partial p_{N}} \frac{\partial p_{N}(t, \theta)}{\partial t_{N}}\right]}\right] .
$$

Equation (59) reflects the impact of uncertainty over the value of 2. High values of 2 tend to depress $\frac{\partial p_{N}}{\partial t_{N}}$, since oligopolistic output determination is based on marginal revenue curves that are steeper than demand curves. Unless $\frac{\partial X_{N}}{\partial p_{N}}$ is strongly affected by $2-$ which is unlikely - then the covariance in the numerator of the term on the right side of (59) is negative. States of the world in which 2 takes a high value are also states of the world in which higher tax subsidies are relatively less effective at stimulating demand. It follows that states of the world in which 2 is small also those in which tax subsidies have a significant impact on resource allocation. The relative ineffectiveness of tax subsidies when needed (i.e., when 2 is large) makes the perfect corrective tax policy smaller in magnitude than it would be if the degree of competition were known with certainty. 
In order to see this relationship more clearly, consider the case of a linear demand curve, for which $\frac{\partial X_{N}(t, \theta)}{\partial p_{N}}$ is constant. In this case, (57) becomes:

$$
E\left[\left(m(t, \theta)+t_{N}\right) \frac{\partial p_{N}(t, \theta)}{\partial t_{N}}\right]=0
$$

In order to interpret (60), it is useful to refer to equation (3), which describes the effect of $t_{N}$ on $p_{N}$ in a partial equilibrium setting. Note that in the assumed case of a linear demand curve, the elasticity of inverse demand for good $N, \eta \equiv \frac{\partial^{2} p_{N}}{\partial x_{N}^{2}} \frac{x_{N}}{\partial p_{N} / \partial x_{N}}$, equals 0. With constant marginal cost as well, expression (3) reduces to

$$
\frac{\partial p_{N}}{\partial t_{N}}=\left\{1+\frac{1+\theta}{n}\right\}^{-1}=\frac{n}{1+n+\theta}
$$

which lies between zero and one (for the realistic cases in which $\theta \geq-1$ ) and is a decreasing function of 2. Denoting the (linear) demand function $X_{N}=a-b p_{N}$, it follows that $\frac{\partial X_{N}}{\partial p_{N}}=-b$, and the pricing equation (52) implies

$$
X_{N}=\frac{n\left[a-b\left(q_{N}+t_{N}\right)\right]}{1+n+\theta}
$$

Combining (52) and (60) - (62) produces the first-order condition:

$$
t_{N} E\left[\frac{n}{1+n+\theta}\right]=E\left[\frac{X_{N}(1+\theta)}{1+n+\theta}\right] \frac{1}{\partial X_{N} / \partial p_{N}}
$$


Since $m=-\frac{X_{N}(1+\theta)}{n\left(\partial X_{N} / \partial p_{N}\right)},(62)$ implies that $\bar{m}=\frac{\left[a-b\left(q_{N}+t_{N}\right)\right]}{\partial X_{N} / \partial p_{N}} E\left[\frac{1+\theta}{1+n+\theta}\right]$. Then (62) and

(63) together imply:

$$
t_{N}=-\bar{m}\left\{\frac{E\left[\frac{1+\theta}{(1+n+\theta)^{2}}\right]}{E\left[\frac{1}{1+n+\theta}\right] E\left[\frac{1+\theta}{1+n+\theta}\right]}\right\}
$$

In order to interpret (64), it is helpful to define $\gamma \equiv \frac{1}{1+n+\theta}$, from which it follows that $(1+\theta)=\frac{1}{\gamma}-n$. Then (64) becomes:

$$
t_{N}=-\bar{m} \frac{E\left[\gamma^{2}\left(\frac{1}{\gamma}-n\right)\right]}{E[\gamma] E[1-n \gamma]}=-\bar{m} \frac{E[\gamma]-n E\left[\gamma^{2}\right]}{E[\gamma]-n\{E[\gamma]\}^{2}}
$$

Defining $\bar{\gamma} \equiv E[\gamma]$, and using the definition of the variance to substitute $\sigma^{2}(\gamma) \equiv E\left[\gamma^{2}\right]-\{E[\gamma]\}^{2}$, it follows from (65) that:

$$
t_{N}=-\bar{m}\left\{1-\frac{\sigma^{2}(\gamma)}{\bar{\gamma}\left(\frac{1}{n}-\bar{\gamma}\right)}\right\}
$$

Since the variance $\sigma^{2}(\gamma) \geq 0$, and the restriction that $\theta \geq-1$ implies that $\frac{1}{n} \geq \bar{\gamma}>0$, it follows that (66) implies that $t_{N}$ is less than or equal to $\bar{m}$ in absolute value. 
Equations (65) and (66) characterize corrective taxation in a way that permits a simple evaluation of the potential importance of the correction due to uncertainty over the appropriate value of 2. Consider, for example, the case in which $n=10$ and ( is uniformly distributed over the interval $(1 / 10,1 / 40)$. Then $\mathrm{E}\left[(]=0.0625, \mathrm{E}\left[\left(^{2}\right]=0.004375\right.\right.$, and (65) implies that $t_{N}=-\bar{m}(0.92)$. If, instead, $n=2$ and 2 is uniformly distributed over the interval $(-1,5)$, then $\mathrm{E}\left[(]=0.231, \mathrm{E}\left[\left({ }^{2}\right]=0.0625\right.\right.$, and (65) implies that $t_{N}=-\bar{m}(0.86)$. Alternatively, if $\mathrm{n}=10$ and 2 is uniformly distributed over the interval $(-1,5)$, then $\mathrm{E}\left[(]=0.0783, \mathrm{E}\left[\left({ }^{2}\right]=0.00625\right.\right.$, and $(65)$ implies that $t_{N}=-\bar{m}(0.93)$. These examples, which need not be representative, share the feature that perfect corrective policy is approximately ten percent smaller in magnitude in the presence of modest uncertainty over the degree of market competition.

\section{Conclusion}

The ability of the government to alter private incentives through the tax system affords policymakers a range of options that are often more attractive than regulatory alternatives. When it is possible to identify imperfectly competitive market structures, an appropriate set of taxes and subsidies can be used to correct misallocations due to oligopolistic price-setting. These taxes and subsidies reflect a tension between the efficiency gains from subsidizing output in the imperfectly competitive sector of the economy and the cost of taxing the rest of the economy to pay for the subsidies. In those cases in which the extent of competition is not known with certainty, a more moderate set of corrective taxes and subsidies is typically indicated.

The focus of this analysis is the efficiency of resource allocation, which, while perfectly appropriate for economic research, represents only a part of the information necessary in order to implement sound policy. Musgrave (1959, p. 157) reminds the reader that "the avoidance of 
excess burden is only one consideration among others in choosing between different taxes." He continues (p. 159), "Society must ask itself what price, in terms of excess burden, it wishes to pay to secure certain policy objectives. In this sense, the narrow criterion of efficiency as avoidance of excess burden must be subordinated to a broader concept of efficiency under which conflicting objectives are reconciled." The reconciliation of these diverse objectives is the task of political and social organizations whose job is made easier by its thoughtful conceptualization in the work of Richard Musgrave and others. 


\section{References}

Auerbach, Alan J., 1985, The theory of excess burden and optimal taxation, in: Alan J. Auerbach and Martin Feldstein, eds., Handbook of Public Economics, vol. 1 (North-Holland, Amsterdam), 61-127.

Auerbach, Alan J. and James R. Hines Jr., 2001, Taxation and economic efficiency, working paper, University of California.

Cournot, Augustin, 1838, Researches Into the Mathematical Principles of the Theory of Wealth, trans. Nathaniel T. Bacon (Macmillan, New York, 1929); reprinted as Of monopoly and of the influence of taxation on commodities produced under a monopoly, in: Richard A. Musgrave and Carl S. Shoup eds., Readings in the Economics of Taxation (Richard D. Irwin, Homewood, IL, 1959), 240-255.

Delipalla, Sofia and Michael Keen, 1992, The comparison between ad valorem and specific taxation under imperfect competition, Journal of Public Economics 49, 351-366.

Diamond, Peter A. and James A. Mirrlees, 1971, Optimal taxation and public production I: Production efficiency and II: Tax rules, American Economic Review 61, 8-27 and 261278.

Edgeworth, F.Y., 1925, The pure theory of taxation, in: F.Y. Edgeworth ed., Papers Relating to Political Economy, vol. 2 (Macmillan, London); reprinted as The pure theory of taxation, in: Richard A. Musgrave and Carl S. Shoup eds., Readings in the Economics of Taxation (Richard D. Irwin, Homewood, IL, 1959), 258-296.

Guesnerie, Roger and Jean-Jacques Laffont, 1978, Taxing price makers, Journal of Economic Theory 19, 423-455.

Higgins, Benjamin, 1943, Post-war tax policy (Part I), Canadian Journal of Economics and Political Science 9; reprinted as Fiscal control of monopoly, in: Richard A. Musgrave and Carl S. Shoup eds., Readings in the Economics of Taxation (Richard D. Irwin, Homewood, IL, 1959), 312-321.

Katz, Michael L. and Harvey S. Rosen, 1985, Tax analysis in an oligopoly model, Public Finance Quarterly 13, 3-20.

Musgrave, Richard A., 1959, The Theory of Public Finance (McGraw-Hill, New York).

Musgrave, Richard A., 1976, ET, OT, and SBT, Journal of Public Economics 6, 3-16.

Myles, Gareth D., 1987, Tax design in the presence of imperfect competition: An example, Journal of Public Economics 34, 367-378. 
Myles, Gareth D., 1989, Ramsey tax rules for economies with imperfect competition, Journal of Public Economics 38, 95-115.

Myles, Gareth D., 1995, Public economics (Cambridge, UK, Cambridge University Press).

Myles, Gareth D., 1996, Imperfect competition and the optimal combination of ad valorem and specific taxation, International Tax and Public Finance 3, 29-44.

Ramsey, F.P., 1927, A contribution to the theory of taxation, Economic Journal 37, 47-61.

Roberts, John and Hugo Sonnenschein, 1977, On the foundations of the theory of monopolistic competition, Econometrica 45, 101-113.

Robinson, Joan, 1933, The economics of imperfect competition (London, Macmillan).

Samuelson, Paul A., approx. 1951, Theory of optimal taxation, unpublished memorandum for the U.S. Treasury; published in: Journal of Public Economics 30, 1986, 137-143.

Sandmo, Agnar, 1975, Optimal taxation in the presence of externalities, Swedish Journal of Economics 77, 86-98.

Seade, Jesus, 1980a, On the effects of entry, Econometrica 48, 479-489.

Seade, Jesus, 1980b, The stability of Cournot revisited, Journal of Economic Theory 23, 15-26.

Stiglitz, Joseph E. and Partha S. Dasgupta, 1971, Differential taxation, public goods and economic efficiency, Review of Economic Studies 38, 151-174.

Suits, Donald B. and Richard A. Musgrave, 1953, Ad valorem and unit taxes compared, Quarterly Journal of Economics 67, 598-604. 


\section{Table 1}

\section{Perfect Commodity Taxes with Stone-Geary Utility Functions}

Basic

Need 1+?
Specific Taxation

$\mathbf{t}_{1}$

$\mathbf{t}_{2}$

$\mathbf{t}_{2}^{*}$

Ad Valorem Taxation

(a) $\mathrm{n}$

0.176

0.176

0.176

0.176

0.176

0.176

$0.0 \quad 0.1$

0.242

0.118

0.242

0.231

0.129

0.240

$\begin{array}{ll}0.0 & 0.2\end{array}$

0.316

0.053

0.316

0.296

0.070

0.320

$-0.1 \quad 0.0$

0.104

0.257

0.257

0.104

0.257

0.257

$\begin{array}{ll}-0.1 & 0.1\end{array}$

0.169

0.214

0.349

0.154

0.225

0.336

$\begin{array}{ll}-0.1 & 0.2\end{array}$

0.244

0.166

0.457

0.210

0.189

0.439

$\begin{array}{llllllll}0.1 & 0.0 & 0.238 & 0.074 & 0.074 & 0.238 & 0.074 & 0.074 \\ 0.1 & 0.1 & 0.300 & 0.003 & 0.115 & 0.296 & 0.007 & 0.118 \\ 0.1 & 0.2 & 0.365 & -0.072 & 0.160 & 0.367 & -0.075 & 0.175\end{array}$

Note: The table presents distortion-minimizing tax rates for an economy in which identical consumers have utility functions given by $U=\left[\left(x_{1}-a\right) x_{2} l\right]^{1 / 3}$, in which $x_{1}$ is consumption of commodity $1, x_{2}$ is consumption of commodity $2, l$ is leisure, and $a$ denotes the consumer's basic need for commodity 1 . Commodity 1 is produced by a competitive industry, while commodity 2 is produced by an imperfectly competitive industry consisting of $n$ firms, each of which selects its output level with a conjectural variation of 2 . Thus, lower values of $[(1+2) / n]$ correspond to greater industry competition.

Consumers have unit wages and unit labor endowments, and constant producer costs of both commodities are fixed at unity as well. The government's revenue requirement equals ten percent of the economy's labor endowment. $t_{1}$ and $t_{2}$ are tax rates on commodities 1 and 2 respectively, while $t_{2}^{*}$ is the total wedge between consumer price and producer cost for commodity 2, inclusive both of the effect of taxes and the markup due to imperfect competition. 